\title{
Properties Of Cellulose Nanofibers Extracted From Eucalyptus And Their Emulsifying Role In The Oil-In- Water Pickering Emulsions
}

\section{Lilian S. Martins}

Federal University of ABC

Ronaldo Gonçalves dos Santos ( $\sim$ rgsantos@fei.edu.br)

FEl's University Centre: Centro Universitario da FEl https://orcid.org/0000-0001-5584-644X

\section{Márcia A. Silva Spinacé}

Federal University of ABC

\section{Research Article}

Keywords: Nanocellulose, Emulsifier, High-pressure homogenization, High-Intensity Ultrasound, Pickering emulsions

Posted Date: April 21st, 2021

DOI: https://doi.org/10.21203/rs.3.rs-413307/v1

License: (c) (i) This work is licensed under a Creative Commons Attribution 4.0 International License. Read Full License

Version of Record: A version of this preprint was published at Waste and Biomass Valorization on June 18th, 2021. See the published version at https://doi.org/10.1007/s12649-021-01498-8. 


\section{Abstract}

In this work, nanocellulose particles were obtained from eucalyptus fibers by high-pressure homogenization (CNF) and by high-intensity ultrasound (SCNF). The nanocellulose was applied as a solid emulsifier for soybean oil in water (O/W) emulsions. The adding of $0.25-1$ wt.\% of both CNF and SCNF produced stable O/W emulsions without conventional surfactants. SCNF emulsions showed the highest stability and displayed the narrowest size distribution. Zeta potential values $(-40$ to $-70 \mathrm{mV})$ indicated an electrical barrier to the droplet coalescence. The rheological behavior of O/W emulsions stabilized with CNF and SCNF was described by the Herschel-Buckley model. O/W emulsions produced with nanocellulose particles behave as shear thinning fluid, and their behavior index ranged from 0.33 to 0.68. Both CNF and SCNF emulsions displayed maximum yield stress at a particle concentration of $0.5 \mathrm{wt} . \%$ and $0.75 \mathrm{wt} . \%$, respectively. Besides, the prepared O/W emulsions using 0.5 to $1.00 \mathrm{wt} \% \mathrm{CNF}$ or SCNF did not showed phase separation until 30 days of rest. The data point out to the feasibility of using nanocellulose as a natural emulsifier, which can replace conventional surfactants.

\section{Novelty Statement}

The wastes biomass from the agriculture and forest activities, are renewable materials currently recognized as a valuable source of energy and chemical products. Cellulose is the main component of lignocellulosic biomass, and it has been converted into value-added materials. Recently, cellulose nanoparticles have been produced to be used as an emulsion stabilizer, replacing conventional surfactants. Nanocellulose particles were successfully generated by means of high-energy ultrasound, an intensive energy process, displaying useful properties to stabilize oil-in-water (O/W) emulsions. Surface properties of cellulose nanoparticles were determined. The equivalent hydrophilic-lipophilic balance for nanoparticles was assessed by comparison with conventional fossil-derived surfactant. The Pickering soya oil-in-water emulsions were very stable, showing their usability as emulsion stabilizers. O/W emulsions display a shear-thinning behaviour.

\section{Introduction}

Biomass-derived products have been pointed out as promising substitutes to fossil products in a variety of applications. Biomass is a renewable source that includes organic materials produced by photosynthesis, living microorganisms of animal origin, vegetable, and algae [1]. Lignocellulosic biomass has a high potential to originate valuable products, because of its intensive energy content. The agricultural and livestock residues, as well as forestry wastes are usual sources of lignocellulosic biomass. The biomass recovered from these residues and wastes are especially important due to their minor impact on the food sector and high conversion to biofuels [2, 3]. Cellulose extracted from lignocellulosic biomass has found valuable applications, such as the production of nanoparticles with industrial usage. Cellulose nanoparticles have been applied as solid colloidal particles, which could be used as a special type of surface-active agents in emulsion stabilization [4-6]. Dispersed liquid systems stabilized by solid particles are termed Pickering emulsions. In these systems, the solid particles adsorb 
irreversibly at fluid-fluid interfaces, increasing emulsion stability $[7,4]$. The particles used in the Pickering emulsions include colloidal silica particles [8], carbon nanotubes [19 9], cyclodextrin [10], poly(lactic acid) microspheres [11] and cellulosic material with at least one dimension in the nanometer scale or nanocellulose $[12,5]$.

Conventional emulsifiers are amphiphilic molecules that contain polar and nonpolar groups on their chemical structure. The emulsifier molecules are oriented in such a way that their hydrophobic and hydrophilic ends interact at the interface between the oil and water phases, composing an interfacial film that defines the properties of the whole system. The adsorption of surface-active molecules in the interface decreases the surface tension and stabilizes disperse particles [13]. Compounds derived from fossil sources are the most commonly used as emulsifier agents in the emulsion formulation. However, petroleum-derived surfactants usually are expensive and obtained from non-renewable sources. Finedivided cellulose can adsorb on the interface and stabilize the system, acting as an alternative emulsifier. Nanocellulose is a renewable promising substitute for petroleum-derived emulsifiers in the oil-in-water $(\mathrm{O} / \mathrm{W})$ emulsion stabilization process because it can eliminate some allergenic and cytotoxicity effects caused by synthetic emulsifiers $[14,6,15,16]$. Besides, nanocellulose can strongly adsorb at the oil-water interface to form a steric barrier during the emulsion formation, protecting the emulsion droplets of flocculation or coalescence [4].

Nanocellulose can be produced by bacteria, marine animals such as tunicates, and extracted from algae, fungi $[17,18]$, and mainly from biomass lignocellulosic materials derived from agriculture and forestry activities $[19,20,21]$. Lignocellulosic fibers are essentially constituted of hemicellulose (20-40 wt.\%), cellulose (40-60 wt.\%), and lignin (10-25 wt.\%) [22]. Cellulose is crystalline and presents strong intermolecular hydrogen bonds between chains and a very stable molecular chemical structure. Consequently, the reduction of cellulose into nanostructured particles requires a high-energy intensification process [23].

Cellulose nanostructures are mainly produced by means of chemical treatments (acid hydrolysis), mechanical methods (ball milling, high-pressure homogenizer, high-Intensity ultrasound, and others), and biological processes (enzymatic hydrolysis) [18,20,23]. Chemical and biological methods have hard disadvantages concerning the production of acidic residues and the process cost [24]. Among the mechanical methods, the high-pressure homogenizer $(\mathrm{HPH})$ can be considered a promising and sustainable alternative for producing cellulose nanofibers due to its simplicity and high efficiency [18]. Nevertheless, the HPH method produces cellulose nanofibers with a wide diameter distribution, which could make the final product reproducibility unfeasible for O/W emulsions [4 7]. On the other side, the high-intensity ultrasound (HIUS) method can be used after HPH to produce cellulose nanofibers (CNF) with improved diameter distribution. The HIUS must generate non-toxic waste, in an aqueous medium, and consume low energy [24]. Specially, the adequate stabilization of the food emulsions is a challenge because of tight requirements for suitable emulsifiers for edible purposes $[25,26]$. Consequently, the interest in sustainable and suitable compounds that act as stabilizers for food-grade emulsions has been growing [27]. 
Emulsions are thermodynamically unstable systems consisting of two immiscible liquids, in which one phase is dispersed in the form of droplets with microscopic or colloidal size and surrounded by a continuous phase $[28,29]$. The natural instability of emulsions arises from the production of a positive Gibbs energy during the mixing process between the continuous and the disperse phase; consequently, O/W emulsions tend to exhibit an ordinary tendency of phase separation $[30,20]$. Aiming to reach a kinetic stabilization that allows their commercialization, most marketable emulsions use expensive and non-renewable emulsifiers constituted mainly by active compounds as a surfactant or surface-active polymers $[30,7,31]$. Emulsified systems are present in several industrial areas, such as petroleum [32,33] cosmetics [34], pharmaceuticals [35], agrochemicals [36], and food [37,25].

The preparation of emulsion generally requires the dispersion of the phases using energy as agitation, homogenization, or ultrasound and the presence of emulsifiers to compensate the natural instability of the system $[27,38]$.

Several studies describe the extraction of CNF from lignocellulosic fibers to act as emulsifying agent. Tonoli et al. (2012) [39] obtained CNF from eucalyptus Kraft pulp by milling and HIUS process ( $80 \mathrm{~W})$ for $7 \mathrm{~h}$. Cheng et al. (2009) [40] evaluated the extraction of CNF from regenerated cellulose fibers, pure cellulose fibers, and microcrystalline cellulose using HIUS ( $1200 \mathrm{~W})$ for $30 \mathrm{~min}$. The use of a highenergy process to prepare the emulsions contributed to increasing the stability of the emulsions. Costa et al. (2018) [27] observed that the use of ultrasound promotes a slower time for emulsion separation compared to the use of rotor-stator. Nechyporchuk et al. (2016) [41] described the rheological behavior of aqueous suspensions of CNF as shear thinning and thixotropic. Karppinen et al. (2012) [42] verified that at high shear rates (from $\sim 10 \mathrm{~s}^{-1}$ ), a continuous increase of shear stress as a function of shear rate. Shearing flow measurements have been used as a tool for the characterization of the cellulose fibrillation degree. In general, an increase of the viscosity as a function of fibrillation level has been reported $[41,43,44]$.

In the $\mathrm{O} / \mathrm{W}$ emulsions with edible triglyceride oils, is commonly seen the broad oil droplet size distribution [45]. The soyabean oil is a mixture of glycerides, mainly $50.8 \%$ of linoleic acid, $22.8 \%$ of oleic acid, and $10.7 \%$ of palmitic acid [46]. The presence of different compounds in the oil allows the formation of a wide range of droplet sizes during emulsification. Besides, the coexistence of dispersed droplets of different sizes can result in the formation of a droplet cluster structure in the emulsions.

Although an extensive number of studies have been devoted to applying nanoparticle as a stabilizer for Pickering emulsions, some surface properties of the cellulose particles are still not fully described to achieve the adequate emulsion stabilization. In this work, the hydrophilicity (from contact angle measurements) and hydrophilic-lipophilic balance (HLB) (from the comparison with conventional emulsifiers) were investigated with regard to their impact on the emulsion stability and rheology. The cellulose nanoparticles (CNF) were extracted from the eucalyptus by means of the HPH process and was used to obtain SCNF samples by means of HIUS. The obtained CNF and SCNF were characterized and 
used as a solid emulsifier in soya oil in water emulsions. Pickering $10 \mathrm{wt} . \%$ oil in water emulsions were prepared using $0.25-1.00 \mathrm{wt}$ \% of CNF or SCNF nanoparticles.

\section{Materials And Methods}

\section{Materials}

Cellulose nanofibers (CNF) were kindly supplied by Suzano Papel e Celulose (SP, Brazil) as a 2.3 wt.\% aqueous suspension from Eucalyptus Grandis extracted using HPH. Commercial soya oil (Liza ${ }^{\circledR}$, Brazil) was used without further purification. Deionized water $(\mathrm{pH} 5.00 \pm 0.01)$ was obtained from the Sppencer ${ }^{\circledR}$ deionizer. Non-ionic ethoxylated nonylphenol surfactants (ULTRANEX ${ }^{\circledR}$ NP) containing different ethoxylation degrees (4 EO, 8 EO, 10 EO, and 100 EO) was supplied by Oxiteno S/A (SP, Brazil).

\section{Production of cellulose nanofibers by HIUS $[47,48]$}

The sonicated cellulose nanofibers (SCNF) were prepared from the dispersion of $10 \mathrm{~g}$ of $2.3 \mathrm{wt} \% \mathrm{CNF}$ aqueous suspension into $150 \mathrm{~mL}$ of deionized water using a high intensity ultrasonic (HIUS, Cole-Parmer brand, CPX750 - $750 \mathrm{~W}$ ) with titanium alloy tip of $13 \mathrm{~mm}$ diameter for $30 \mathrm{~min}$ at $525 \mathrm{~W}$ and $20 \mathrm{kHz}$. The system was immersed in a cooling bath to keep the mixture temperature always constant and below 25 ${ }^{\circ} \mathrm{C}$ during the process. After sonicating, SCNF was maintained at $5{ }^{\circ} \mathrm{C}$ for $24 \mathrm{~h}$ and then, rotated in a centrifuge (Nova Instruments, NI1803, Brazil) for $7 \mathrm{~min}$ at $8000 \mathrm{rpm}$ (about $1.120 \mathrm{~g}$ ) to remove the residual water.

The energy consumption for extraction of nanocellulose can be determined based on the methods reported in the literature $[49,50,51]$ for calculation of energy consumption of nanocellulose production. Frone et al. (2011) [52] extracted nanocellulose from microcrystalline cellulose using only HIUS for 10-20 min which consumed 330-1333 MWh/ton.

\section{Characterization of Soybean oil}

The $\mathrm{pH}$ measurement of the soybean oil was performed in triplicate on a digital bench $\mathrm{pHmeter}(\mathrm{pH} 1800$, Gehaka). The water content of soybean oil was determined in triplicate using a Karl-Fischer V30 volumetric titrator, Mettler Toledo. The mixture 60/40 wt.\% methanol/chloroform was used to solubilize the soybean oil in water titration test. Soybean oil density and viscosity were measured on the Anton Paar Stabinger SVM 3000 Viscometer at temperatures ranging from 10 to $70^{\circ} \mathrm{C}$.

Four O/W emulsions were prepared using $1 \mathrm{wt} . \%$ of a commercial emulsifier ULTRANEX ${ }^{\circledR}$ NP with different ethylene oxide numbers (EO) - 4 EO, 8 EO, 10 EO, and 100 EO. Stability tests of Ultranex-stabilized emulsions were used to assess the optimal hydrophilic-lipophilic balance (HLB) of the soybean oil. The most relevant properties of soybean oil are summarized in Table 1.

\section{CNF and SCNF characterization}




\section{CNF and SCNF morphology}

Atomic force microscopy (AFM), NX10 Park Systems, was applied to assess the CNF and SCNF morphology. The GMR Nanosensor tip was used at a resonance frequency of $7 \mathrm{kHz}$ under a constant force of $2.8 \mathrm{~N} / \mathrm{m}$. The AFM images were analyzed using Gwyddion ${ }^{\circledR}$ software.

\section{Thermogravimetric analysis}

Thermogravimetric analyses (TGA) of CNF and SCNF samples were performed using a Netzsch STA 449 F3 model from Jupiter ${ }^{\circledR}$ in the temperature range from 25 to $600{ }^{\circ} \mathrm{C}$ under nitrogen atmosphere, with a heating rate of $10^{\circ} \mathrm{C} \cdot \mathrm{min}^{-1}$ and flow rate of $50 \mathrm{~mL} / \mathrm{min}$.

\section{Fourier Transform Infrared Spectrophotometer (FTIR)}

Fourier-transform infrared spectroscopy (FTIR) measurements of CNF and SCNF samples were performed on the ATR mode (Perkin Elmer Frontier, $100 \mathrm{FT}-\mathrm{IR}$ ), from 4000 to $650 \mathrm{~cm}^{-1}$ with $4 \mathrm{~cm}^{-1}$ resolution and 32 scans in an environment with controlled temperature and humidity.

\section{Wettability behavior}

The hydrophilicity of CNF or SCNF sample was assessed from the wettability determination, using an optical tensiometer (Attension Theta model, Biolin Scientific, Sweden). The sample preparation for wettability analysis consists of drying suspensions of water/CNF (or SCNF) in an oven at $100{ }^{\circ} \mathrm{C}$ until whole water removal to forming a solid film. Wettability was determined by means of the static contactangle measurement from the deposition of a deionized water droplet $(\sim 34 \mu \mathrm{L})$ on the surface of CNF and SCNF films. The deposited droplet image was recorded using a high-speed video camera, and the droplet profile was numerically resolved and adjusted to the Young-Laplace equation.

\section{Surface tension of CNF and SCNF aqueous suspensions}

The surface tension of water/CNF or SCNF suspensions was determined in triplicate at $20{ }^{\circ} \mathrm{C}$ using a Theta Lite optical tensiometer (Attension, Sweden) which captures successive images of the drop of fluid under analysis. One droplet of the solutions containing $0.25 ; 0.50 ; 0.75$ and $1 \mathrm{wt} . \%$ of CNF or SCNF was formed at the tip of a syringe. The shape of the drop was analyzed using the axisymmetric drop shape analysis (ADSA) method, based on the Laplace equation, to determine the surface tension as a function of time. Surface tension measurements were based on a methodology previously reported by Vieira et al. (2018) [53].

\section{Preparation and characterization of 0/W Pickering Emulsions}

\section{O/W emulsifying procedure}


O/W emulsions with 10 wt.\% of soybean oil and 90 wt.\% of aqueous suspension of nanocellulose particles (CNF or SCNF) were prepared. The concentration of nanocellulose particles in the aqueous dispersions were $0.25,0.50,0.75$, and $1 \mathrm{wt}$. $\%$. The procedure for $\mathrm{O} / \mathrm{W}$ emulsion preparation was based on the previous emulsification methodology reported by Santos et al. (2014) [54]. O/W emulsions were prepared by dispersing soybean oil in an aqueous dispersion at the specified temperature $\left(21-23^{\circ} \mathrm{C}\right)$ and then they were mixed for a total period of 1 min using a high-intensity ultrasound system (HIUS $525 \mathrm{~W}$ and $20 \mathrm{kHz}$, Cole-Parmer brand, CPX750-750 W). The emulsion type was confirmed by dilution tests. The $\mathrm{pH}$ of the aqueous phase was adjusted to 5.0. Nanocellulose aqueous suspensions were previously prepared with concentration ranging from 0.25 to $1 \mathrm{wt}$.\%. Firstly, the soybean oil was added to the nanocellulose aqueous suspension and stirred for $30 \mathrm{~s}$ using HIUS. The pre-emulsion was slightly mixed by manual stirring for $10 \mathrm{~s}$. Finally, the mixture was stirred again for another $30 \mathrm{~s}$ using HIUS, resulting in the final emulsion.

\section{Emulsion stability}

The stability of the emulsions with $0.25,0.50,0,75$ and $1.00 \mathrm{wt} . \%$ of CNF or SCNF was evaluated using measures of phase separation of the emulsions when subjected to the bottle test using centrifugation (Nova Instruments Centrifuge, N11803). In this test, the emulsions were placed in $60 \mathrm{~mL}$ graduated test tubes and subjected to centrifugation at $2000 \mathrm{rpm}$ (centrifugal force of $280 \mathrm{~g}$ ) for $10 \mathrm{~min}$. at $25^{\circ} \mathrm{C}$. In addition, the stability of the emulsions with $0.25,0.50,0.75$ and $1.00 \mathrm{wt}$.\% of CNF or SCNF, and emulsions with $1.00 \mathrm{wt} . \%$ of ULTRANEX® NP (with $4 \mathrm{EO}, 8 \mathrm{EO}, 10 \mathrm{EO}$, and $100 \mathrm{EO}$ ) were assessed under rest after 30 days. In these tests, the volume of separated water was monitored as a function of time. Both in the bottle test and in the assessment at rest, stability was evaluated as the volumetric percentage of separated aqueous phase, based on the amount of water separated from the emulsion after the test or aqueous phase resolved (AR), according to Eq. 1.

$\mathrm{AR}=$ (amount of aqueous phase separated after testing $/$ total amount of water added) $\times 100$ (1)

\section{Z-potential}

Zeta potential of the O/W emulsions was assessed using a Zeta Potential Meter (Zetasizer NanoZS). Zpotential values were related to the emulsion stability.

\section{Droplet size and size distribution}

The droplet size and size distribution were investigated with an optical microscope (Zeiss Axio Scope A.1) coupled to a CCD camera for image acquisition. The images were analyzed, and the diameters of the droplets were individually measured using Image $J^{\circledR}$ software. The particle size was analyzed for populations of 800 droplets, and classified according to the statistical class interval. The stable emulsions were assessed by examining the emulsion's average droplet size, evaluated using the Sauter diameter, $\mathrm{D}_{3,2}$, and by examining the droplet size distribution. The Sauter diameter was calculated according to Equation 2. 


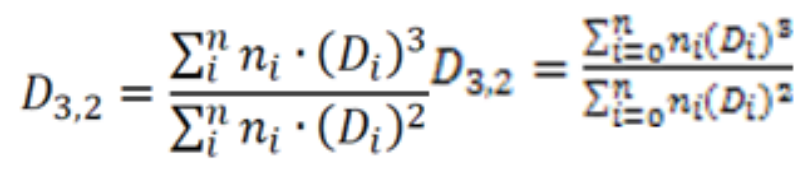

\section{Rotational rheology}

The rheological behavior of the samples was evaluated through the flow and viscosity curves. The flow and viscosity curves of the CNF and SCNF aqueous suspensions (1 wt.\%), soya oil, and O/W emulsions were obtained using an MCR-502 model rheometer (Anton Paar). The rotational test was carried out on $25 \mathrm{~mm}$ parallel plates under controlled shear rate in the range of 0.01 to $100 \mathrm{~s}^{-1}$ at $24^{\circ} \mathrm{C}$.

\section{Results And Discussion}

\section{Characterization of CNF and SCNF samples}

Figure 1 presents AFM micrographs and the weighted average diameter for CNF ( $a$ and $c$ ) and SCNF ( $b$ and d) samples.

CNF and SCNF that were submitted to the HPH and HIUS process, showed nanofibers of cellulose with random orientation, as shown in Figure $1 \mathrm{a}$ and $\mathrm{b}$.

The weighted average diameter values determined from AFM for the samples to be close to $100 \mathrm{~nm}$ for SCNF and $236 \mathrm{~nm}$ for CNF with a length higher than $1 \mu \mathrm{m}$, indicating that sonication was effective to fibrillate CNF sample. This fibrillation occurs because during sonication homogenizing process promotes an increase in the collision rate between the particles generating high shearing.

Figure $1 \mathrm{c}$ and $\mathrm{d}$ show that the length distribution of the CNF was from 20 to $700 \mathrm{~nm}$ and from 50 to 250 nm for SCNF.

Wang et al. (2017) [23] extract CNF from eucalyptus citriodora by HPH and obtained particles with the diameter ranged from 20 to $100 \mathrm{~nm}$ and length in the range of $900-1300 \mu \mathrm{m}$.

The use of high-intensity ultrasound produces narrower and monodispersed SCNF samples. Cellulose fibers with a smaller diameter and shorter length are more suitable to be used as emulsion stabilizers because of the increased surface area. Fine-powdered particles can accommodate better onto the oil droplet surface, constituting an interfacial film that acts as a barrier to coalescence $[7,27]$.

The TGA/DTG curves and FTIR spectra of the CNF and SCNF samples are shown in Figure 2.

Both CNF and SCNF samples presented two mass-loss processes under heating assessed by the first derivative on TGA curves (Figure 2b). The first mass-loss process was found at about $80{ }^{\circ} \mathrm{C}$ and it is attributed to the evaporation of residual humidity. The second mass-loss process occurring at about 205$390{ }^{\circ} \mathrm{C}$ is related to cellulose degradation that include the mechanisms of depolymerization, dehydration, 
cleavage of secondary bonds and formation of charred residue [55]. The onset temperatures ( $\left.T_{\text {onset }}\right)$ for CNF and SCNF occurred at 205 and $215^{\circ} \mathrm{C}$, respectively, indicating an increase in the thermal stability (about $10^{\circ} \mathrm{C}$ ) of the SCNF sample which could be induced by the sonication of the nanofibers samples. The degradation temperature for SCNF is higher due the fibrillation of the CNF that occurred during the HIUS process, which results in the partial removal of the amorphous fraction such as hemicellulose, lignin or amorphous cellulose from the CNF sample. Whereas the maximum degradation temperatures were found at 321 and $336^{\circ} \mathrm{C}$ for CNF and SCNF, respectively. The solid residue at $600{ }^{\circ} \mathrm{C}$ of the CNF and SCNF are about 23 and $19 \%$, respectively.

On the other hand, no significant difference in the chemical composition of the CNF and SCNF samples was observed, as shown by the cellulose characteristic peaks on the FTIR spectra in Figure $2 \mathrm{c}$ and $\mathrm{d}$. The band at about $895 \mathrm{~cm}^{-1}$ is related to the asymmetric deformation of the $-\mathrm{CH}_{2}$ groups in cellulose. The bands at about $1040 \mathrm{~cm}^{-1}$ and $1060 \mathrm{~cm}^{-1}$ are characteristics respectively of the symmetrical and asymmetrical stretching of C-O-C groups. The band at $1160 \mathrm{~cm}^{-1}$ can be attributed to the stretching of the $\mathrm{C}-\mathrm{O}-\mathrm{C}$ antisymmetric bond present predominantly in cellulose, although it may also be present in other polysaccharides such as hemicellulose [55].

The band at about $3327 \mathrm{~cm}^{-1}$ observed for CNF and SCNF is associated with the vibration of intermolecular hydrogen bonds of the cellulose [55]. However, this band is more intense for the SCNF sample, indicating that sonification facilitated access to hydroxyls groups and consequently interaction with water, which may increase the hydrophilicity. As expected, none of the samples presented bands at $1730 \mathrm{~cm}^{-1}$ is assigned to stretching of unconjugated $-\mathrm{C}=0$ group in hemicellulose, and the bands at 1600 and $1510 \mathrm{~cm}^{-1}$ which are attributed to the $\mathrm{C}=\mathrm{C}$ stretch vibration that is characteristic of lignin [56-60].

The average contact angle $(\theta)$ for the CNF sample was $79.5( \pm 5.2)$ degrees, while $\theta$ value was approximately zero for SCNF. The data show that sonification can change the nanocellulose surface wettability from neutral to fully water-wet. The difference in hydrophilicity of nanocellulose samples extracted by mechanical methods (HPH or HIUS) was also observed by Costa et al. (2018) [27], Tang et al. (2019) [61] and Yang, Li and Fan (2020) [62]. Costa et al. (2018) [27] which studied CNF-stabilized emulsions produced using HPH or HIUS in different conditions verified that both process promote a decrease in contact angle values of CNF samples. In the ultrasound process, the cavitation phenomenon can promote partial degradation of crystalline regions of CNF resulting in the formation of hydrophobic domains, and consequently, reduction of contact angle values. A water-wet behavior points out to a better particle dispersion in aqueous phase, while a neutral behavior represents a better accommodation on the oil-water interface. The variation of the static contact angle $(\theta)$ revealed the occurrence of surface regions with different wet-behavior, which explain the neutral wetting behavior attributed to some cellulose samples [62]. Good interaction between CNF and SCNF particles and the aqueous dispersed phase can prevent the droplet coalescence and coagulation processes.

\section{Characterization of soybean oil}


The $\mathrm{pH}$, moisture content, density, viscosity, surface tension, and hydrophilic-lipophilic balance of soybean oil are presented in Table 1.

The commercial soybean presented pH close to neutral (slightly acid) at $25^{\circ} \mathrm{C}$. According to McClements (1999) [25] low pH value for the oil influences the formation and characteristics of the O/W emulsion, in a way that more acidic media facilitates the coalescence of oil droplets. Dynamic viscosity and density curves of soybean oil were performed as a function of temperature. The fitting of an Arrhenius-type equation for the viscosity allows determining the activation energy for viscous flow $\left(E_{a}\right)$ for soybean oil as $27.5 \mathrm{~kJ} \cdot \mathrm{mol}^{-1}$.

The surface tension of the soybean oil is slightly higher than that for the oleic acid [63]. The optimum hydrophilic-lipophilic balance $\left(\mathrm{HLB}_{\mathrm{opt}}\right)$ for the oil emulsification was determined by measuring $\mathrm{O} / \mathrm{W}$ emulsion stability. For determination of $\mathrm{HLB}_{\text {opt }}$, the soybean oil in water emulsions were prepared using 1 wt. \% of ULTRANEX ${ }^{\circledR}$ NP with HLB values of $8.9,12.3,13.3$, and 19 , and these emulsions presented Sauter diameter $\left(D_{3,2}\right)$ values of $5.25,3.49,6.64$, and 5.75 , respectively. A shallow minimum is set for the $8 \mathrm{EO}$ surfactant, which has an HLB equal to 12.3. This means that oil emulsification requires a hydrophilic surface-agent. Contact angle measurements have proved that CNF and SCNF achieved hydrophilic properties, being prone to act in the soybean oil emulsions.

\section{Properties of CNF and SCNF aqueous suspensions}

Figure 3 shows the surface tension of cellulose nanofibers aqueous dispersions. It can be observed that water suspensions with 0.25 wt.\% of CNF or SCNF presented a similar value of surface tension (about 71 $\mathrm{mN} / \mathrm{m}$ ), close to the water surface tension. The increase of the cellulose nanofibers concentration promotes decreases in the surface tension of the dispersions, reaching until $64.8 \mathrm{mN} / \mathrm{m}$ for CNF and 49.9 $\mathrm{mN} / \mathrm{m}$ for SCNF suspension at a concentration of $0.75 \mathrm{wt} . \%$. For concentrations higher than $0.25 \mathrm{wt} . \%$, the surface tension of SCNF dispersions was substantially smaller than that of CNF dispersion. It was not possible to determine the surface tension of the $1 \mathrm{wt}$.\% of SCNF suspension because its high viscosity avoids the suspension droplet insertion into the small opening-diameter syringe. These results indicate a higher surface activity for the sonicated sample (SCNF), which is probably related to the SCNF smaller diameter and higher hydrophilicity that would result in a more adequate surface arrangement and better coverage of the surface area.

Flow curves (Figure 4a) evaluated under shear-rate ranging from $10^{-2}$ to $10^{2} \mathrm{~s}^{-1}$, and viscosity curves (Figure $4 \mathrm{~b}$ ) describe the rotational rheology of aqueous suspensions containing $1 \mathrm{wt} . \%$ of CNF and SCNF.

The flow curves in Figure 4a show that the yield stress $(25.6$ ( \pm 4.3)) for SCNF dispersion was found to be approximately 10 -fold higher than the yield stress $(2.6( \pm 0.1))$ produced by CNF dispersion. Besides, SCNF suspensions are more viscous than CNF suspensions across the fully shear rate range studied. Both SCNF and CNF suspension exhibit high viscosity at low shear. On this point, the suspension viscosity at $1 \mathrm{~s}^{-1}$ is about $3,000 \mathrm{mPa}$ s for CNF and about $48,000 \mathrm{mPa} \mathrm{s}$ for SCNF suspensions. The 
higher viscosity and higher yield stress indicate a higher level of fibrillation of SCNF that can result in a strong 3D gel network. The higher fibrillation degree of SCNF compared to CNF is supported by AFM data.

The viscosity of the dispersion is higher than pure water viscosity, indicating the presence of an arrangement of CNF and SCNF solid particles in suspensions. CNF dispersion displayed lower resistance in the initial flow and more pronounced shear-thinning behavior than SCNF dispersion, which is related to the droplet size and surface properties. The viscosity curves in Figures $4 \mathrm{~b}$ display a significant shear thinning behavior for CNF and SCNF suspensions with $1 \mathrm{wt} . \%$ of cellulose particles. Shear thinning behavior has been often reported to cellulose nanoparticle dispersion $[4,18,41,43,44,64,65]$.

Flow curves obtained from rotational rheology measurements for nanocellulose dispersion samples were modeled to assess the rheological behavior. The Herschell-Buckley rheological model (Equation 3) was fitting to the rheological data from Figures $4 \mathrm{~b}$.

$$
\tau=K \cdot(\gamma)^{n}+\tau_{0}
$$

In Equation 3, $\mathrm{t}$ represents the shear stress, $\mathrm{g}$ represents the shear rate, $\mathrm{K}$ is the consistency index, $\mathrm{n}$ is the behavior index, and $t_{0}$ is the yield stress. HB model was accurately fitted to the experimental data, producing an adjusted coefficient of 0.99. CNF aqueous suspensions were evaluated in the range of 0.01$1000 \mathrm{~s}^{-1}$, while SCNF aqueous suspension was evaluated in the range 0.1-100 s-1. Disturbs on the viscosity at high shear rate produced a randomicity of data that became unfeasible to adjust any rheological model at shear rates higher than $100 \mathrm{~s}^{-1}$ for SCNF aqueous suspension, which is probably related to SCNF particle aggregation in solution that can produce coarse particle dispersion. The rheological parameters calculated from the Herschel-Buckley model are presented in Table 2. The behavior index confirms the intense pseudoplastic behavior for both suspensions.

Sabet et al. (2016) [66] reported similar results of the rheological behavior of microfibrillar cellulose aqueous suspensions prepared using different levels of refining energies The microfibrillar cellulose selfassociates on an entangled 3D gel network. At shear stress higher than the yield stress, shearing forces deform and break the network structure resulting in shear-thinning behavior. After structure breaking, microfibrillar cellulose to align along the shear direction promoting further shear thinning at higher shear rates region.

Zeta potential ( $\zeta$ ) of aqueous suspensions of CNF and SCNF containing $1 \mathrm{wt} . \%$ of dispersed particles were - 8.2 and $-13.2 \mathrm{mV}$, respectively. Sonicated eucalyptus cellulose presented in previous works has shown a similar range for zeta potential $(-19.1 \pm 0.4 \mathrm{mV})$ [39]. Lu et al. (2014) [67] has stated that $|\zeta|>30$ $\mathrm{mV}$ is related to the high dispersion capacity in water, while |Z| values lower than $30 \mathrm{mV}$ indicate low dispersion stability. Thus, the low value of absolute zeta potential of the aqueous suspensions of CNF and SCNF indicates that their surface charges would favor the agglomeration of the nanocellulose.

\section{Characterization of O/W Pickering Emulsions}

Page $11 / 29$ 
O/W emulsions, named as ECNF and ESCNF, respectively, were obtained from the intermittent emulsification of $10 \mathrm{wt}$ \% of soybean oil in $90 \mathrm{wt} . \%$ of aqueous dispersion with CNF or SCNF concentrations of $0.25,0.5,0.75$, and $1 \mathrm{wt}$.\%. Figure $5 \mathrm{a}$ and $5 \mathrm{c}$ show images of ECNF and ESCNF that were prepared using cellulose nanofibers without hydrophobic modifications.

The stability of ECNF and ESCNF was verified by means of centrifugation (Fig. 5a) and at rest (Fig. 5c), and it was observed a strong tendency to creaming for both emulsions with CNF or SCNF. Gestranius et al. (2016) [68] related the similar results for dodecane/water emulsions with CNF extracted from bleached birch pulp, TEMPO-oxidized cellulose nanofibrils (T-CNF) and CNC.

The bottle test resulted in percentages of aqueous phase-resolved as a function of the concentration of the CNF or SCNF, as shown in Figures $5 \mathrm{~b}$ and $5 \mathrm{~d}$.

Even for emulsions with a low concentration of cellulose nanofibers $(0.25 \mathrm{wt} \%)$, the formation of an $\mathrm{O} /$ W emulsion occurred for both emulsions that used CNF or SCNF. This concentration is less than that generally required when conventional surfactants are used [7]

The blue dotted line shown in Figure 5a referring to the emulsions after centrifugation highlights the separation of the oil phase. The red dotted line (Fig. 5a) marks the separation of aqueous phase-resolved whose quantification is shown in Fig. $5 b$.

Figure $5 \mathrm{~b}$ shows the results of percentages of aqueous phase-resolved as a function of the concentration of the CNF or SCNF and indicate that ESCNF dispersion has the highest stability, irrespective of the nanoparticle concentrations. The high nanoparticle concentration in the aqueous dispersion promotes high stability of Pickering emulsions.

Figure $5 c$ displays a comparative picture of ESCNF, ECNF, and emulsion prepared with ethoxylated nonylphenol. At $1 \mathrm{wt}$ \% suspension concentration, the emulsion stability after 30 days at rest followed the order: ESCNF > ECNF > ULTRANEX. The ethoxylated nonylphenol produced the most unstable emulsions. Emulsions prepared with ULTRANEX ${ }^{\circledR}$ NP 40 presented $37.5 \%$ aqueous phase-resolved after 10 days, and $87.5 \%$ after 30 days. On the other hand, no phase separation was observed for the ECNF and ESCNF at the same concentration (1 wt. \%), and in $0.25 \mathrm{wt}$ \% content, ESCNF present more stability compared to ECNF after 30 days at rest (Figure $5 \mathrm{~d}$ ). Concluding, O/W emulsions using CNF or SCNF

This result is very promising because the prepared oil-in-water emulsions using 0.5 to $1.00 \mathrm{wt} . \% \mathrm{CNF}$ or SCNF did not showed phase separation until 30 days of rest. Gestranius et al. (2016) [68] reported for dodecane / water emulsions containing from 0.1 to $1.5 \mathrm{wt} \%$ of CNF and TEMPO-CNF a phase separation in $1 \mathrm{~h}$ and $50 \mathrm{~h}$, respectively. Yokota et al. (2019) [69] prepared O/W emulsions with 0.1 or $0.2 \mathrm{wt} \%$ of CNF extracted by aqueous counter collision system using various non-polar solvents and observed phase separation before $1 \mathrm{~h}$. 
CNF without modification can promote stability for long time of Pickering emulsion. Bai et al. (2018) [70] explored the synergism between $\mathrm{CNC}$ and $\mathrm{CNF}$ in order to increase the stability of Pickering emulsions. For O/W Pickering emulsions with $\mathrm{CNC}$ and low oil volume fraction, the induction of depletion stabilization due adding CNF occurred only for the non-adsorbing CNF, that form a novel system with spherical droplets and the high-aspect cellulose nanorods. This system stabilize Pickering emulsions for an extended period (7 months).

Nanocellulose adsorbs irreversibly in a way that the emulsion can be efficiently stabilized [7]. The higher stability of ESCNF is probably related to the higher surface activity of the SCNF [71]. The bottle test confirms that CNF and SCNF can efficiently act as a stabilizer of O/W interfaces. The high continuousphase viscosity, as found in CNF and SCNF aqueous dispersions, contributes to increasing the emulsion stability, reducing de-stabilization phenomena that come from interfacial mass diffusion [72].

The slower creaming rate due to the formation of smaller oil droplets could also be associated with an easier accommodation of nanocellulose with a lower aspect ratio onto the interface of the droplet during emulsification using ultrasound.

The stability of the emulsions was also assessed by means of zeta potential measurements as shown in Figure 6.

All emulsions showed $\zeta$-potential greater than $-30 \mathrm{mV}$, similar to zeta potential values presented by Hong, Kim, Lee (2018) [73], which used a mixture of conventional emulsifiers (Spans ${ }^{\circledR}$ and Tweens ${ }^{\circledR}$ ). All O/W emulsions prepared with CNF or SCNF showed ל-potential values between about - 45 to - $60 \mathrm{mV}$ (Figure 6), which are lower than the values of the aqueous suspensions with $1 \mathrm{wt}$ \% of CNF and SCNF (- 8.2 and $13.2 \mathrm{mV}$, respectively). Costa et al. (2018) [27] used HIUS and HPH and Ni, Li and Fan (2020) [74] used $\mathrm{HPH}$ to produce $\mathrm{O} / \mathrm{W}$ emulsions with $\mathrm{CNF}$, and observed that application of HPH or HIUS led to a decrease of $\zeta$-potential values for the emulsions. The HPH and HIUS process can promote the contact of cellulose with oxygen resulting in the generation of negative charge on the cellulose nanofibers surface due to the partial oxidation of the particles.

The zeta potential values indicate that there is sufficient repulsive force between the dispersed droplets to keep them away from each other to prevent their coalescence [62].

The emulsification degree is directly related to the droplet size [45].

Figure 7 shows the optical micrographs of ECNF and ESCNF, and particle size distributions. All emulsions micrographics display discrete oil droplets with Sauter diameters $\left(D_{3,2}\right)$ lower than $47 \mu \mathrm{m}$.

Li, Wang, Wu (2019) [4] prepared O/W emulsions using a high shear homogenizer by mixing dodecane $(10-50 \mathrm{v} \%)$ and different contents $(0.1-0.5 \mathrm{wt}$.\%) of nanofibrillated bacterial cellulose (average width = $127-97 \mathrm{~nm}$ ) suspensions, obtaining $D_{3,2}$ of about $12-13 \mu \mathrm{m}$. Smaller $D_{3,2}$ is associated with the higher 
kinetic stability because of the reduction of the effects of the gravitational phase separation, once the droplets velocity is proportional to the radius square.

Cunha et al. (2014) [75] extract CNF from softwood sulfite pulp fibers using enzyme, mechanical beating and homogenization process, and cellulose nanocrystals (CNC) by acid hydrolysis. CNF and CNC were used in hexane:water (20:80) emulsions.

Figure 7 shows that ECNF and ESCNF present a narrow droplet size distribution, which illustrates the efficiency of the emulsification process. The droplet size presented an average diameter of $3.3 \pm 1.2$ and $2.6 \pm 0.8 \mu \mathrm{m}$ for CNF and CNC, respectively in the stabilized emulsions.

The optical microscopy images of ECNF and ESCNF (Figure 7) show the presence of clusters of droplets. Cunha et al. (2014) [75] who prepared Pickering oil-water emulsions using CNC and CNF, observed clusters of droplets only for emulsions with CNF. They attributed these agglomerations to the high aspect ratio $(\sim 100-150)$ and long length of CNF $(>1 \mu \mathrm{m})$.

Lu et al. 2019 reported the formation of droplet clusters in the O/W emulsions [45] and proposed two main routes. By route I, well-coated small droplets are attached around the surface of larger ones (white arrows in Figure 7) forming a planet-satellite-like structure. The route II considered that most particle bundles are flexible and it can connect several droplets themselves and the simultaneous emulsification of these connected droplets in the different fiber parts can form a grape cluster-like structure (dashed white line in Figure 7). Thus, the observed droplet cluster structure was the result of the formation of these clusters by the two routes and by the strong repulsion of both due to the high steric hindrance as two clusters approach [45].

Figure 8 shows the relationship between the Sauter diameter $(D 3,2)$ as a function of CNF and SCNF concentrations in the $\mathrm{O} / \mathrm{W}$ emulsions. ECNF showed lower D3,2 values for all concentrations of the CNF compared to ESCNF.

The flowability of the edible emulsion system is an important aspect of the preparation, storage, and final food products. Figure 9 shows the viscosity curves and flow curves for the ECNF and ESCNF with different concentrations of cellulose nanoparticles.

Rheological curves for both ECNF and ESCNF describe a typical shear-thinning behavior, characterized by decreasing in viscosity along with the growth of the shear rate. The rheological behavior of ECNF and ESCNF is similar to those from emulsions described in previous works $[74,31,45]$. At a given shear rate, the viscosity of suspensions increased as a function of CNF and SCNF content. The increase of CNF and SCNF content promotes slight changes in the shear-thinning profile of the $\mathrm{O} / \mathrm{W}$ emulsions, suggesting that the rheology behavior of the emulsions is affected by the content of the nanofibrils. Similar results have been reported by Li et al. (2020) [76].

Morphology of the CNF and SCNF nanofibrils favor the entanglement with each other to form a strong network structure, which is difficult to destroy at low shear rate. At high shear rate, nanofiber networks are 
supposed to be destroyed, decreasing the ECNF and ESCNF viscosity as the concentration of dispersed particles increases. Therefore, the flow field became increasingly disturbed, due to the introduction of a higher number of particles on the flow line, resulting in a higher rate of energy dissipation, and consequently increasing the emulsion viscosity $[54,77,78]$.

The Herschel-Buckley model (Eq. 3) was fitted to the emulsion rheological data in Figure 9 and the Herschel-Buckley rheological parameters for $10 \mathrm{wt}$ \% soybean oil in water emulsions are presented in Table 3.

Equation 4 gives the limiting viscosity $(\mu 0)$, which represents the viscosity at a shear stress equivalent to the yield stress.

$$
\mu_{0}=k * \gamma_{0}^{n-1}+\tau_{0} * \gamma_{0}^{-1}
$$

Table 3 shows the rheological parameters to the Herschel-Buckley model for the $10 \mathrm{wt}$.\% O/W Pickering emulsions stabilized with cellulose nanoparticles under the concentration range of 0.25-1 wt.\%. The O/W emulsions present a complex thixotropic and pseudoplastic behavior. The thixotropy phenomena are related to the deformation of the dispersed oil droplets under shear and their orientation along the flow direction $[54,79]$. The behavior index shows that emulsions produced with SCNF display more intense pseudoplastic phenomena, mainly in low particle concentration. The increase of the cellulose particle concentration makes thinner the emulsions, with higher viscosity reduction to the emulsions containing SCNF. This observation agrees with the data for droplet size and droplet size distribution shown in Figures 7 and 8 that show emulsions produced with SCNF resulted in higher droplet size and higher polydispersity, which allow higher droplet deformability and lower flow resistance.

The higher particle content and higher consistency index K. K-parameter strongly affects the emulsion viscosity. An increase of 4 -fold in the particle concentration produces approximately an increase of 180fold and 40 -fold on the $\mathrm{K}$ values for ECNF and ESCNF, respectively. Anyway, the emulsion viscosity was always lower than 42 Pa.s. The emulsions containing $1 \mathrm{wt}$.\% of solid particles did not produce yield stress. The limiting viscosity $\left(\mu_{0}\right)$ was affected by the Herschel-Buckley model parameters.

\section{Conclusions}

CNF and SCNF nanocellulose samples showed characteristics suitable to be applied as an emulsifier agent in $\mathrm{O} / \mathrm{W}$ Pickering emulsions. High intensity ultrasonic application resulted in smaller diameter sizes and more water-wet particles, improving the emulsifying process. Low concentrations ( 0.25 - $1 \mathrm{wt}$ \% \%) of CNF and SCNF resulted in stable emulsions, even in the absence of conventional surfactants. $\zeta$-potential values (- 40 to $-70 \mathrm{mV}$ ) showed that cellulose nanoparticles provided enough stability to the droplet coalescence, indicating electric repulsion forces acting between droplets. The Pickering emulsions stabilized with CNF and SCNF showed a strongly pseudoplastic rheological behavior, with substantial yield stress. The prepared O/W emulsions using 0.5 to $1.00 \mathrm{wt}$ \% CNF or SCNF did not showed phase 
separation until 30 days of rest. The results point out to the possibility of using nanocellulose obtained from the paper industry byproducts as a natural emulsifying agent. Nanocellulose is obtained from renewable sources and cellulose nanoparticles were proved to be able to replace conventional fossil surfactants.

\section{Declarations}

\section{Funding}

This work was supported by The Coordination of Superior Level Staff Improvement, CAPES (grant number 1751838), the São Paulo Research Foundation, FAPESP (grant numbers 2010/17804-7, 2011/00156-5) and the National Council for Scientific and Technological Development, CNPq (grant number 310410/2010-0).

\section{Conflicts of interest/Competing interests}

The authors confirm that there are no conflicts of interest associated with this publication.

\section{Availability of data and material (data transparency)}

The authors confirm total data transparency in this publication.

\section{Code availability}

The authors confirm they have used Microsoft word, Microsoft Excel, Origin Lab software and built-in software to the data assessment and analysis.

\section{References}

[1] Santos, RG; Alencar, AC. (2020) Biomass-derived syngas production via gasification process and its catalytic conversion into fuels by Fischer Tropsch synthesis: A review. International Journal of Hydrogen Energy, 45 (36) 18114-18132.

[2] Voloshin RA, Rodionova MV, Zharmukhamedov SK, Veziroglu TN, Allakhverdiev SI. (2016) Biofuel production from plant and algal biomass. International Journal of Hydrogen Energy, 41:17257-73.

[3] Demirbas A. (2008) Biofuels sources, biofuel policy, biofuel economy and global biofuel projections. Energy Convers Manag; 49, 2106-16.

[4] Li, Q., Wang, Y., Wu, Y. (2019). Flexible cellulose nanofibrils as novel pickering stabilizers: The emulsifying property and packing behavior. Food Hydrocolloids, 88, 180-189.

[5] Li, X., Ding, L., Zhang, Y., Wang, B., Jiang, Y., Feng, X., Mao, Z., Sui, X. (2019). Oil-in-water Pickering emulsions from three plant-derived regenerated celluloses. Carbohydrate Polymers, 207, 755-763. 
[6] Gong, X., Wang, Y., Chen, L. (2017). Enhanced emulsifying properties of wood-based cellulose nanocrystals as Pickering emulsion stabilizer. Carbohydrate Polymers, 169, 295-303.

[7] Kalashnikova, I., Bizot, H., Bertoncini, P., Cathala, B., Capron, I. (2013). Cellulosic nanorods of various aspect ratios for oil in water Pickering emulsions. Soft Matter, 9(3), 952-959.

[8] Binks, B. P., Lumsdon, S. O. (2000). Effects of oil type and aqueous phase composition on oil-water mixtures containing particles of intermediate hydrophobicity. Physical Chemistry Chemical Physics, 2, 2959-2967.

[9] Briggs, N., Raman, K. A. Y., Barrett, L., Brown, C., Li, B., Leavitt, D., Aichele, C. P., Crossley, S.(2018). Stable pickering emulsions using multi-walled carbon nanotubes of varying wettability. Colloids and Surfaces A: Physicochemical Engineering Aspects,537, 227-235.

[10] Hu, J. W., Yen, M. W., Wang, A. J., Chu, I. M. (2018). Effect of oil structure on cyclodextrin-based Pickering emulsions for bupivacaine topical application. Colloids and Surfaces B: Biointerfaces, 161, 5158.

[11] Zhu, J. Y., Tang, C. H., Yin, S. W., Yang, X. Q. (2018). Development and characterization of novel antimicrobial bilayer films based on Polylactic acid (PLA)/Pickering emulsions. Carbohydrate Polymers, 181, 727-735.

[12] Klemm, D., Kramer, F., Moritz,S., Lindström,T., Ankerfors, M., Gray, D., Dorris, D. (2011). Nanocelluloses: A New Family of Nature-Based Materials. Angewandte Chemie International Edition, 50, 5438-5466.

[13] Shaw, D. J. (1992) Introduction to Colloid and Surface Chemistry. Oxford: Butterworth-Heinemann, 4 ed.

[14] De Pretto, C., Giordano, R.L.C., Tardioli, P.W., Costa, C.B.C. Possibilities for Producing Energy, Fuels, and Chemicals from Soybean: A Biorefinery Concept. Waste Biomass Valor (2018) 9:1703-1730.

[15] Ojala, J.; Sirviö, J. A.; Liimatainen, H. (2016) Nanoparticle emulsifiers based on bifunctionalized cellulose nanocrystals as marine diesel oil-water emulsion stabilizers. Chemical Engineering Journal, $288,312-320$.

[16] Li, X., Li, J., Gong, J., Kuang, Y., Mo, L., Song, T. (2018). Cellulose nanocrystals (CNCs) with different crystalline allomorph for oil in water Pickering emulsions. Carbohydrate Polymers, 183, 303-310.

[17] Panagopoulou, E., Tsouko, E., Kopsahelis, N., Koutinas, A., Mandala, I., Evageliou, V. (2015). Olive oil emulsions formed by catastrophic phase inversion using bacterial cellulose and whey protein isolate. Colloids and Surfaces A: Physicochemical Engeneering Aspects, 486, 203-210.

[18] Abdul Khalil, H. P. S., Davoudpour, Y., Islam, N., Mustapha, A., Sudesh, K., Dungani, R., Jawaid, M. (2014). Production and modification of nanofibrillated cellulose using various mechanical processes: A 
review. Carbohydrate Polymers,99, 649-665.

[19] George, J., Sabapathi, S. N. (2015). Cellulose nanocrystals: synthesis, functional properties, and applications. Nanotechnology, Science and Applications, 8, 45-54.

[20] Vallejos, M. E., Felissia, F. E., Area, M.C., Ehman, N.V., Tarrés, Q., Mutjé, P. (2016). Nanofibrillated cellulose (CNF) from eucalyptus sawdust as a dry strength agent of unrefined eucalyptus handsheets. Carbohydrate Polymers, 139, 99-105.

[21] Perrin L, Gillet G, Gressin L, Desobry S. (2020) Interest of Pickering Emulsions for Sustainable Micro/Nanocellulose in Food and Cosmetic Applications. Polymers, 12, 2385-2399.

[22] Yang, H., Yan, R., Chen, H., Lee, D. H., Zheng, C. (2007). Characteristics of hemicellulose, cellulose and lignin pyrolysis. Fuel, 86, 1781-1788.

[23] Wang, Y., Wei, X., Li, J., Wang, F., Wang, Q., Zhang, Y. Kong, L. (2017). Homogeneous isolation of nanocellulose from eucalyptus pulp by high pressure homogenization. Industrial Crops \& Products, 104, 237-241.

[24] Pokhrel, N., Vabbina, P. K., Pala, N. (2016). Sonochemistry: Science and Engineering. Ultrasonics Sonochemistry, 29, 104-128.

[25] McClements, D. J. (1999). Food Emulsions: Principles, Practice and Techniques. New York: CRC Press.

[26] McClements, D. J., Jafari, S. M. (2018). Improving emulsion formation, stability and performance using mixed emulsifiers: A review. Advances in Colloid and Interface Science, 251, 55-79.

[27] Costa, A. L. R., Gomes A., Tibolla, H., Menegalli, F. C., Cunha, R. L. (2018). Cellulose nanofibers from banana peels as a Pickering emulsifier: High-energy emulsification processes. Carbohydrate Polymers, $194,122-131$.

[28] Schramm, L. L. (2005). Emulsions, Foams, and Suspensions: Fundamentals and Applications. WileyVCH GmbH \& Co., Weinheim, $465 \mathrm{f}$.

[29] Derkach, S. (2018). Rheology of emulsions. Advances in Colloid and Interface Science, 151, 1-23.

[30] Rosen, M. (1989). Surfactants and interfacial phenomena. John Wiley \& Sons.

[31] Zhang, H., Qian, Y., Chen, S., Zhao, Y. (2019). Physicochemical characteristics and emulsification properties of cellulose nanocrystals stabilized $\mathrm{O} / \mathrm{W}$ pickering emulsions with high $-\mathrm{OSO}_{3}$ - groups. Food Hydrocolloids, 96, 267-277. 
[32] Santos, R. G., Bannwart, A. C., Briceño, M. I., Loh, W. (2011). Physico-chemical properties of heavy crude oil-in-water emulsions stabilized by mixtures of ionic and non-ionic ethoxylated nonylphenol surfactants and medium chain alcohols. Chemical Engineering Research and Design, 89(7), 957-967.

[33] Lee, J., Babadagli, T. (2019). Optimal design of pickering emulsions for heavy oil recovery improvement. Journal of Dispersion Science and Technology,

https://doi.org/10.1080/01932691.2019.1650754.

[34] Yorgancioglu, A., Bayramoglu, E. E. (2013). Production of cosmetic purpose collagen containing antimicrobial emulsion with certain essential oils. Industrial Crops and Products, 44, 378-382.

[35] Paukkonen, H., Kunnari, M., Laurén, P., Hakkarainen, T. Auvinen, V. V., Oksanen, T., Koivuniemi, R., Yliperttula, M., Laaksonen, T. (2017). Nanofibrillar cellulose hydrogels and reconstructed hydrogels as matrices for controlled drug release. International Journal of Pharmaceutics, 532, 269-280.

[36] Xu, C., Cao, L., Zhao, P., Zhou, Z. (2018). Emulsion-based synchronous pesticide encapsulation and surface modification of mesoporous silica nanoparticles with carboxymethyl chitosan for controlled azoxystrobin release. Chemical Engineering Journal, 348, 244-254.

[37] Corral, M. L., Cerrutti, P., Vázquez, A., Califano, A. (2017). Bacterial nanocellulose as a potential additive for wheat bread. Food Hydrocolloids, 67, 189-196.

[38] Solans, C., Solé, I. (2012). Nano-emulsions: Formation by low-energy methods. Current Opinion in Colloid \& Interface Science, 17, 246-254.

[39] Tonoli, G. H. D.; Teixeira, E. M.; Corrêa, A. C., Marconcini, J. M., Caixeta, L. A., Pereira-da-Silva, M. A., Mattoso, L. H. C. (2012). Cellulose micro/nanofibres from Eucalyptus kraft pulp: Preparation and properties. Carbohydrate Polymers,89, 80-88.

[40] Cheng, Q., Wang, S., Rials, T. (2009). Poly(vinyl alcohol) nanocomposites reinforced with cellulose fibrils isolated by high intensity ultrasonication. Composites: Part A, 40, 218-224.

[41] Nechyporchuk, O, Belgacem, M. N., Pignon, F. (2016). Current Progress in Rheology of Cellulose Nanofibril Suspensions. Biomacromolecules, 17, 2311-2320.

[42] Karppinen, A., Saarinen, T., Salmela, J., Laukkanen, A., Nuopponen, M., Seppala, J. (2012). Flocculation of microfibrillated cellulose in shear flow. Cellulose, 19, 1807-1819.

[43] Herrick, F. W., Casebier, R., L., Hamilton, J. K., Sandberg, K. R. (1983). Microfibrillated cellulose: morphology and accessibility. Journal Applied of Polymer Science Polymer Symposium,37, 797-813.

[44] Gruneberger, F; Kunniger, T.; Zimmermann, T., Arnold, M. (2014). Rheology of nanofibrillated cellulose/acrylate systems for coating applications, Cellulose, 21, 1313-1326. 
[45] Lu Y., Qian, X., Xie, W., Zhang, W., Huang, J., Wu, D. (2019). Rheology of the sesame oil-in-water emulsions stabilized by cellulose nanofibers. Food Hydrocolloids, 94, 114-127.

[46] Perkins E.G., Chapter 2. Composition of Soyas and Soya Products Practical Handbook of Soya Processing and Utilization D. R. Erickson Ed.- 2015 - Technology \& Engineering, AOCS Press Urbana, IL, United Soya Board, St. Louis, Missouri, USA, 1995.

[47] Wang, S.; Cheng, Q. A (2009). A novel process to isolate fibrils from cellulose fibers by high-intensity ultrasonication, part 1: process optimization. Journal of Applied of Polymer Science, 113, 1270-1275.

[48] Bussemaker, M.J.; Zhang, D. (2013). Effect of ultrasound on lignocellulosic biomass as a pretreatment for biorefinery and biofuel applications. Industrial Engineering Chemistry Research, 52, 3563-3580.

[49] Nechyporchuk, O.; Belgacem, M.N.; Bras J. (2016). Production of cellulose nanofibrils: a review of recent advances. Industrial Crops and Products, 93, 2-25.

[50] Lu, H.; Zhang, L.; Liu, C.; He, Z.; Zhou, X.; Nil, Y. (2018) A novel method to prepare lignocellulose nanofibrils directly from bamboo chips. Cellulose, 25, 7043-7051.

[51] Ewulonu, C.M.; Liu, X.; Wu, M.; Huang, Y. (2019) Ultrasound-assisted mild sulphuric acid ball milling preparation of lignocellulose nanofibers (LCNFs) from sunflower stalks (SFS). Cellulose, (26) 7, 43714389.

[52] Frone, A.N.; Panaitescu, D.M.; Donescu, D.; Spataru, C.I.; Radovico, C.; Trusga, R.; Somoghi, R. (2011). Preparation and characterization of PVA composites with cellulose nanofibers obtained by ultrasonication. BioResources, (6) 1, 487-512.

[53] Vieira, L. B., Casimiro, M. W., Santos, R. G. (2018). Surface tension of aqueous amoxicillin+Peg systems. Colloid and Interface Science Communication, 24, 93-97.

[54] Santos, R. G., Bannwart, A. C., Loh, W. (2014). Phase segregation, shear thinning and rheological behavior of crude oil-in-water emulsions. Chemical Engineering Research and Design, 92, 1629-1636.

[55] Spinacé, M. A. S., Lambert C. S., Fermoselli, K. K. G., De Paoli, M. A. (2009). Characterization of lignocellulosic curaua fibres. Carbohydrate Polymers, 77, 47-53.

[56] Azrina, Z.A.Z.; Beg, M.D.H.; Rosli, M.Y.; Ramli, R.; Junadi, N.; Alam, A.K.M.M. (2017). Spherical nanocrystalline cellulose (NCC) from oil palm empty fruit bunch pulp via ultrasound assisted hydrolysis. Carbohydrate Polymers, 162, 115-120.

[57] Tomak, E.D.; Ay, N.; Topaloglu, E.; Gumuskaya, E.; Yildiz, U.C. (2013) An FT-IR study of the changes in chemical composition of bamboo degraded by brown-rot fungi. International Biodeterioration \& Biodegradation, 85, 131-138. 
[58] Manzato, L.; Rabelo, L.C.A.; Souza, S.M.; Silva, C.G.; Sanches, E.A.; Rabelo, D.; Mariuba, L.A.M.; Simonsen, J. (2017) New approach for extraction of cellulose from tucumã's endocarp and its structural characterization. Journal of Molecular Structure, 1143, 229-234.

[59] Özgenç, O.; Durmaz, S.; Boyaci, I.H.; Eksi-Kocak, H. (2017) Determination of chemical changes in heattreated wood using ATR-FTIR and FT Raman spectrometry. Spectrochimica Acta Part A: Molecular and Biomolecular Spectroscopy, 171, 395-400.

[60] Tibolla, H.; Pelissari, F.M.; Rodrigues, M.I.; Menegalli, F.C. (2017) Cellulose nanofibers produced from banana peel by enzymatic treatment: Study of process conditions. Industrial Crops and Products, 95, 664674.

[61] Tang, C., Chen, Y., Luo, J., Low, M. Y., Shi, Z., Tang, J., \& Tam, K. C. (2019). Pickering emulsions stabilized by hydrophobically modified nanocellulose containing various structural characteristics. Cellulose, 26(13), 7753-7767.

[62] Zhai, X., Lin, D., Liu, D., Yang, X. (2018). Emulsions stabilized by nanofibers from bacterial cellulose: New potential food-grade Pickering emulsions. Food Research International, 103, 12-20.

[63] Chumpitaz, L.D.A.; Coutinho, L.F.; Meirelles, A.J.A. Surface tension of fatty acids and triglycerides. J. Am. Oil Chem. Soc. 1999, 76, 379-382.

[64] Paximada, P., Tsouko, E., Kopsahelis, N., Koutinas, A. A. (2016). Bacterial cellulose as stabilizer of o/w emulsions. Food Hydrocolloids, 53, 225-232.

[65] Silva C. E.P.; Tam, K. C.; Bernardes, J. S.; Loh, W. (2020). Double stabilization mechanism of O/W Pickering emulsions using cationic nanofibrillated cellulose. Journal of Colloid and Interface Science,574, 207-216.

[66] Sabet, S.S., Martinez, M., Olson, J. (2016). Shear rheology of micro-fibrillar cellulose aqueous suspensions. Cellulose, 23, 2943-2953.

[67] Lu, Q., Lu, P. M., Piao, J. H., Xu, X. L., Chen, J., Zhu, L., Jiang, J. G. (2014). Preparation and physicochemical characteristics of an allicin nanoliposome and its release behavior. Food Science Technology, 57, 686-695.

[68] Gestranius, M., Stenius, P., Kontturi, E., Sjöblom, J., \& Tammelin, T. (2017). Phase behaviour and droplet size of oil-in-water Pickering emulsions stabilised with plant-derived nanocellulosic materials. Colloids and Surfaces A: Physicochemical and Engineering Aspects, 519, 60-70.

[69] Yokota, S., Kamada, K., Sugiyama, A., \& Kondo, T. (2019). Pickering emulsion stabilization by using amphiphilic cellulose nanofibrils prepared by aqueous counter collision. Carbohydrate polymers, 226, 115293. 
[70] Bai, L., Huan, S., Xiang, W., \& Rojas, O. J. (2018). Pickering emulsions by combining cellulose nanofibrils and nanocrystals: phase behavior and depletion stabilization. Green Chemistry, 20(7), 15711582.

[71] Fujisawa, S., Togawa, E., Kuroda, K. (2017). Nanocellulose-stabilized Pickering emulsions and their applications. Sci Technol Adv Mater, 18(1), 959-971.

[72] Chevalier, Y., Bolzinger, M. A. (2013). Emulsions stabilized with solid nanoparticles: Pickering emulsions. Colloid surface A-physicochemical Engineering. Aspects, 439, 23-34.

[73] Hong, I. K., Kim, S. I., Lee, S. B. (2018). Effects of HLB value on oil-in-water emulsions: droplet size, rheological behavior, zeta-potential, and creaming index. Journal of Industrial and Engineering Chemistry, 67, 123-131.

[74] Ni, Y., Li, J., \& Fan, L. (2020). Production of nanocellulose with different length from ginkgo seed shells and applications for oil in water Pickering emulsions. International journal of biological macromolecules, 149, 617-626.

[75] Cunha, A. G., Mougel, J. B., Cathala, B., Berglund, L. A., \& Capron, I. (2014). Preparation of double Pickering emulsions stabilized by chemically tailored nanocelluloses. Langmuir, 30(31), 9327-9335.

[76] Li, Q., Chen, P., Li, Y., Li, B., Liu, S. (2020). Construction of cellulose-based Pickering stabilizer as a novel interfacial antioxidant: A bioinspired oxygen protection strategy. Carbohydrate Polymers, 229, 115395.

[77] Zanotti, M.A.G., Santos, R.G. (2019) Thixotropic behavior of oil-in-water emulsions stabilized with ethoxylated amines at low shear rates. Chem. Eng. Technol., 42(2), 432-443.

[78] Jutakridsada, P., Pimsawat, N., Sillanpää, M., Kamwilaisak, K. (2020) Olive oil stability in Pickering emulsion preparation from eucalyptus pulp and its rheology behavior. Cellulose, 27, 6189-6203.

[79] Shafiei-Sabet, S., Martinez, M., Olson, J. (2016) Shear rheology of micro-fibrillar cellulose aqueous suspensions. Cellulose, 23, 2943-2953.

\section{Tables}

Table 1. Properties of the soya oil. 


\begin{tabular}{ll}
\hline Property & Value \\
\hline $\mathrm{pH}$ at $25^{\circ} \mathrm{C}$ & $6.68(0.20)$ \\
Water content $(\%)$ & $0.091(0.013)$ \\
Density $\left(\mathrm{g} / \mathrm{cm}^{3}\right)$ at $20^{\circ} \mathrm{C}$ & $0.9191(0.0001)$ \\
Viscosity $(\mathrm{mPa}$. $)$ at $20^{\circ} \mathrm{C}$ & $63.76(0.19)$ \\
Surface tension $(\mathrm{mN} / \mathrm{m})$ at $20^{\circ} \mathrm{C}$ & $36.1(0.5)$ \\
Emulsification-required $\mathrm{HLB}^{*}$ & 12.3 \\
\hline
\end{tabular}

*HLB - Hydrophilic-lipophilic balance.

Table 2. Rheological parameters of the Herschel-Buckley model for CNF and SCNF aqueous suspensions.

\begin{tabular}{llll}
\hline Sample & $\tau_{\circ}$ & $\mathrm{K}$ & $\mathrm{N}$ \\
\hline $\mathrm{CNF}$ & $2.6(0.1)$ & $0.42(0.06)$ & $0.58(0.02)$ \\
SCNF & $25.6(4.3)$ & $26.8(4.2)$ & $0.43(0,04)$ \\
\hline
\end{tabular}

Table 3. Parameters of the Herschel-Buckley model as a function of concentration of the CNF and SCNF of the emulsions.

\begin{tabular}{lcccccccr}
\hline \multirow{2}{*}{$\begin{array}{c}\text { Particle } \\
\text { concentration (wt.\%) }\end{array}$} & \multicolumn{2}{c}{0.25} & \multicolumn{2}{c}{0.50} & \multicolumn{2}{c}{0.75} & \multicolumn{1}{c}{1.00} \\
\hline$\tau_{\mathbf{0}}$ & $\mathbf{C N F}$ & SCNF & CNF & SCNF & CNF & SCNF & CNF & SCNF \\
$\mathbf{n}$ & $0.42(0.06)$ & $0.38(0.13)$ & $1.36(0.21)$ & $0.0(0.0)$ & $0.54(0.27)$ & $1.43(0.34)$ & 0.0 & 0.0 \\
K (Pa.s") & $0.68(0.06)$ & $0.48(0.08)$ & $0.53(0.04)$ & $0.46(0.02)$ & $0.42(0.02)$ & $0.45(0.02)$ & $0.37(0.01)$ & $0.33(0.01)$ \\
$\mathbf{R}^{2}$ & $0.037(0.01)$ & $0.19(0.1)$ & $0.34(0.10)$ & $0.70(0.07)$ & $1.82(0.19)$ & $1.37(0.18)$ & $6.76(0.37)$ & $7.77(0.40)$ \\
& 0.93 & 0.95 & 0.96 & 0.98 & 0.99 & 0.99 & 0.99 & 0.99 \\
\hline
\end{tabular}

\section{Figures}



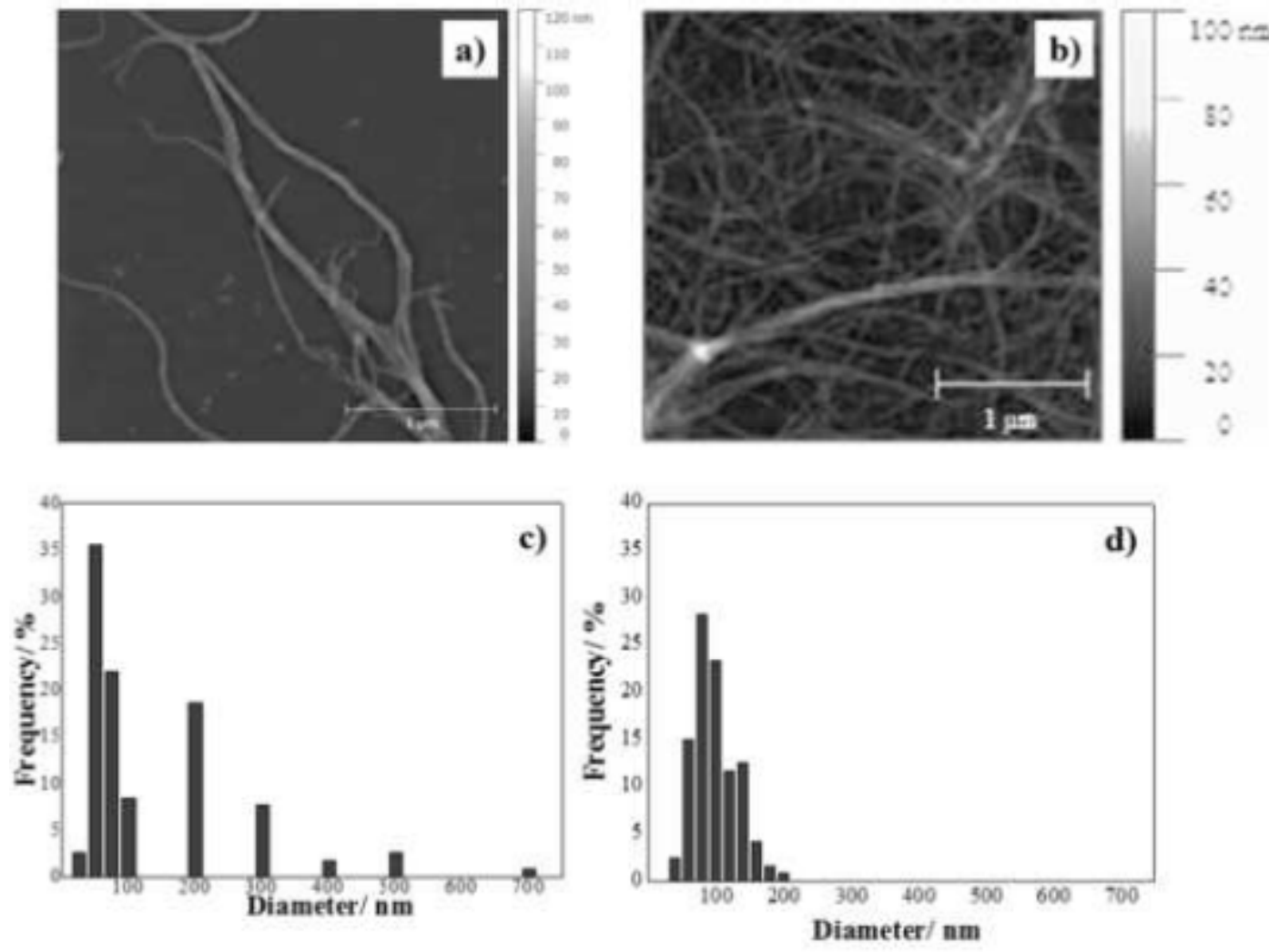

Figure 1

AFM micrograph and histograms of the diameter distribution of CNF (a and c) and SCNF (b and d).
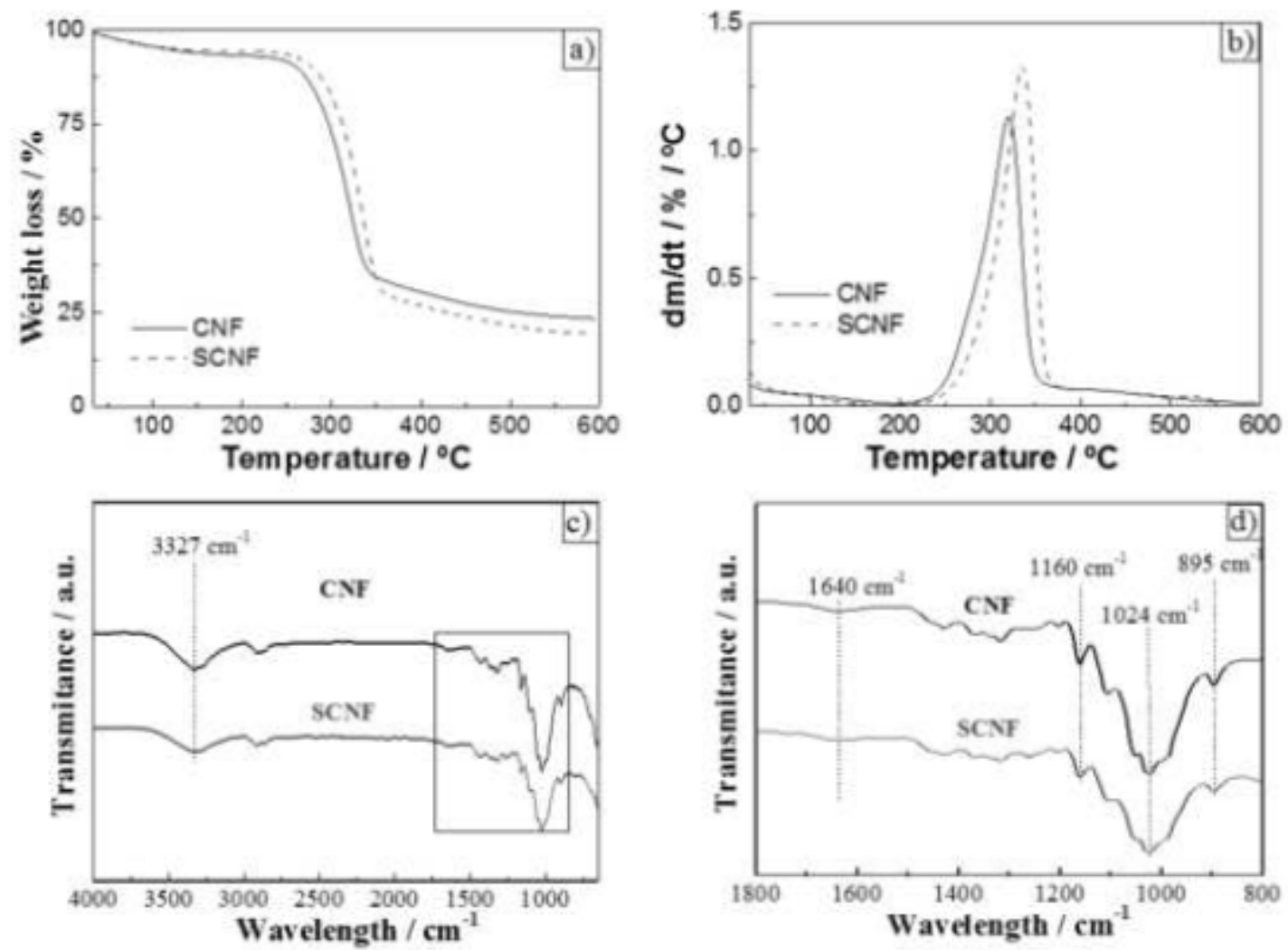

Figure 2 
TGA curves (a), DTG curves (b), and FTIR spectra of the CNF and SCNF samples in the range: (c) 4000 $650 \mathrm{~cm}-1$ and d) $1800-800 \mathrm{~cm}-1$.

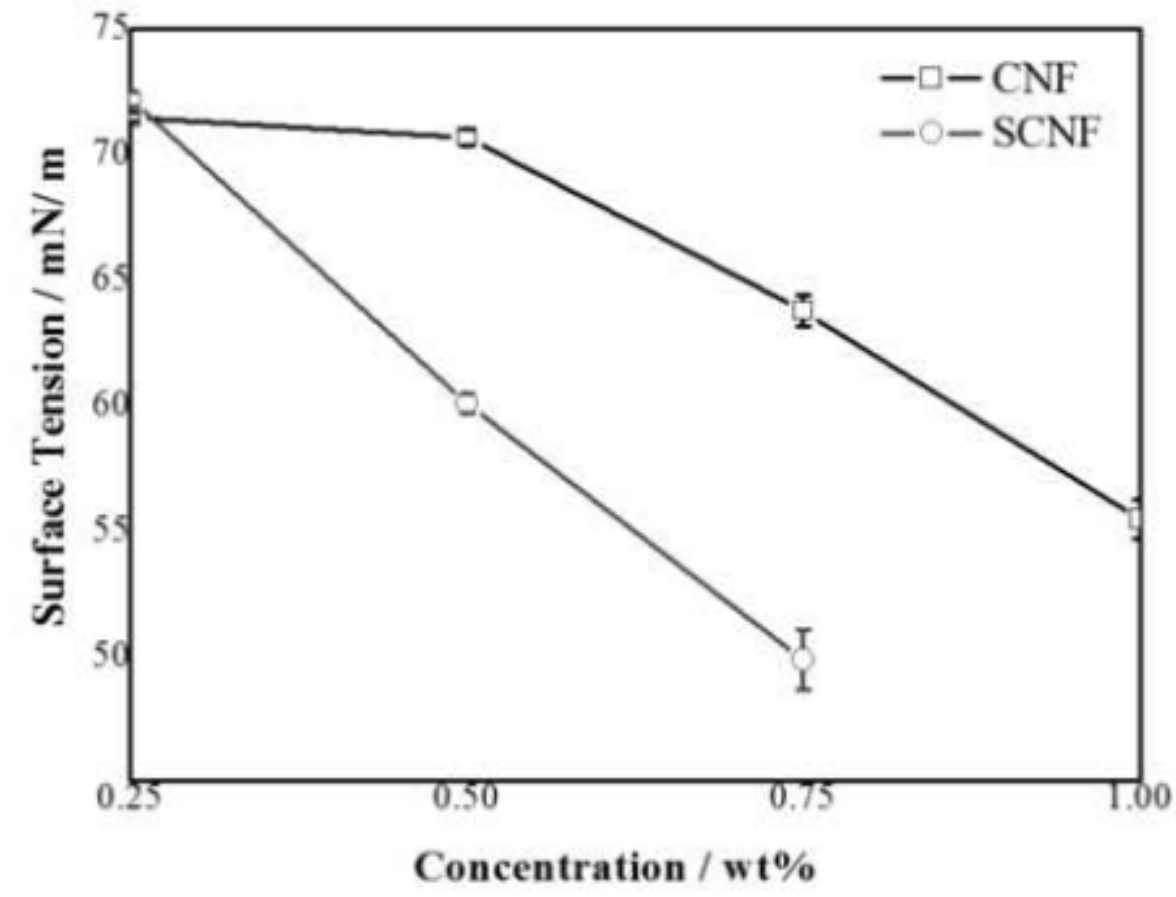

\section{Figure 3}

Equilibrium surface tension of water/cellulose nanofiber suspensions as a function of CNF and SCNF concentration.
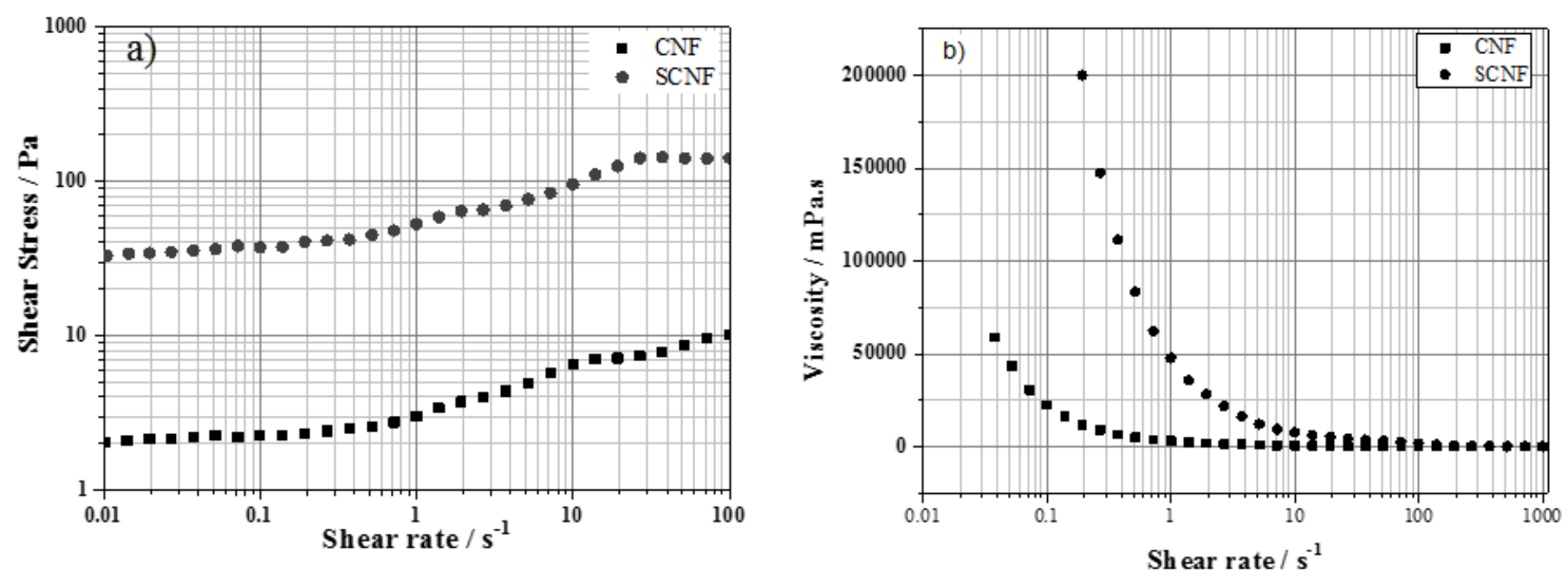

Figure 4

(a) Flow curves for aqueous suspensions of cellulose nanofiber; (b) viscosity curves for $1 \mathrm{wt. \%}$ aqueous suspensions of CNF and SCNF particles. 

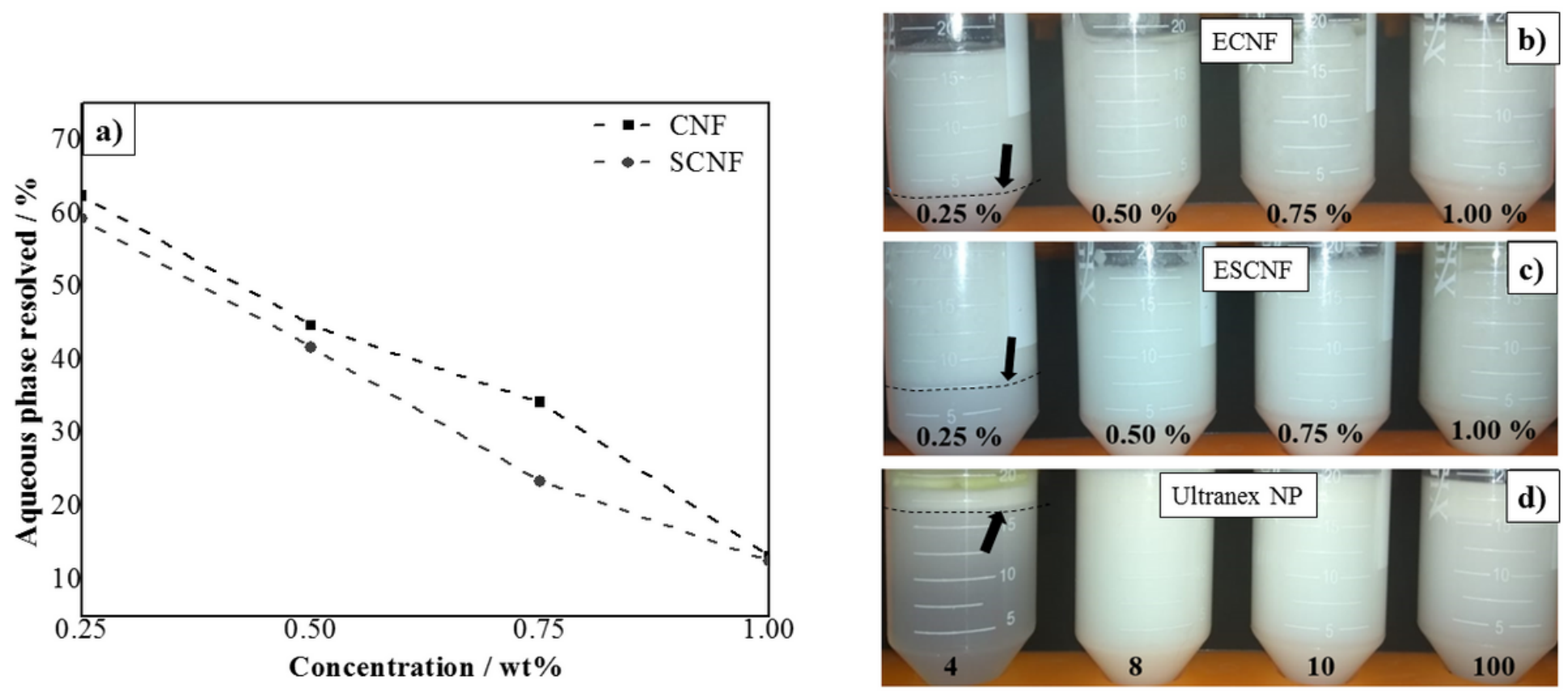

Figure 5

(a). Photographs of the O/W emulsions with $0.25 ; 0.50 ; 0.75$ and 1 wt.\% of CNF or SCNF before and after centrifugation; (b) Aqueous phase resolved (expressed as volume percentage, Vol.\%) for O/W emulsions as a function of concentration of CNF and SCNF after centrifugation (c) Photographs of the O/W emulsions with $0.25 ; 0.50 ; 0.75$ and 1 wt.\% of CNF or SCNF and O/W emulsions with 1 wt.\% of commercial emulsifier ULTRANEX® NP with $n=4,8,10$ and 100; all before and after 30 days of rest.

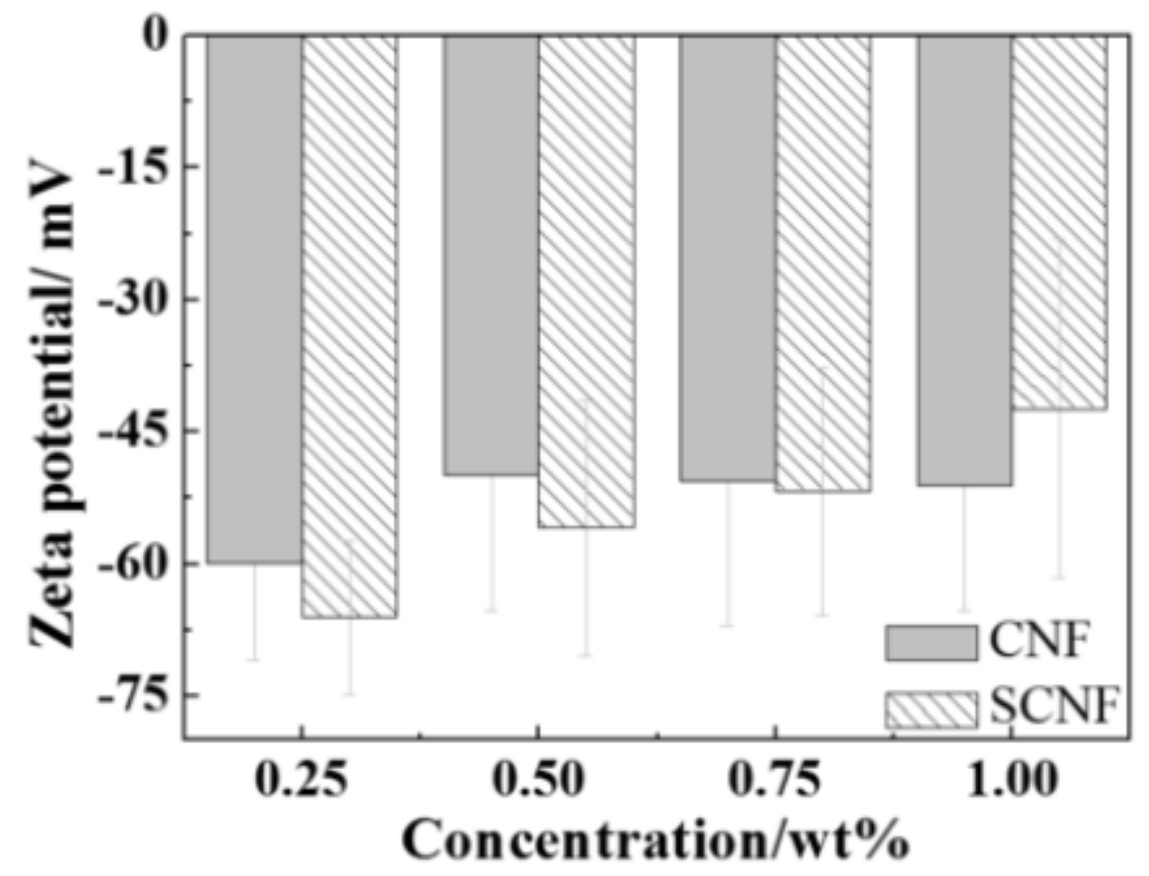

Figure 6 
Zeta potential of O/W Pickering emulsions as a function of CNF and SCNF content.
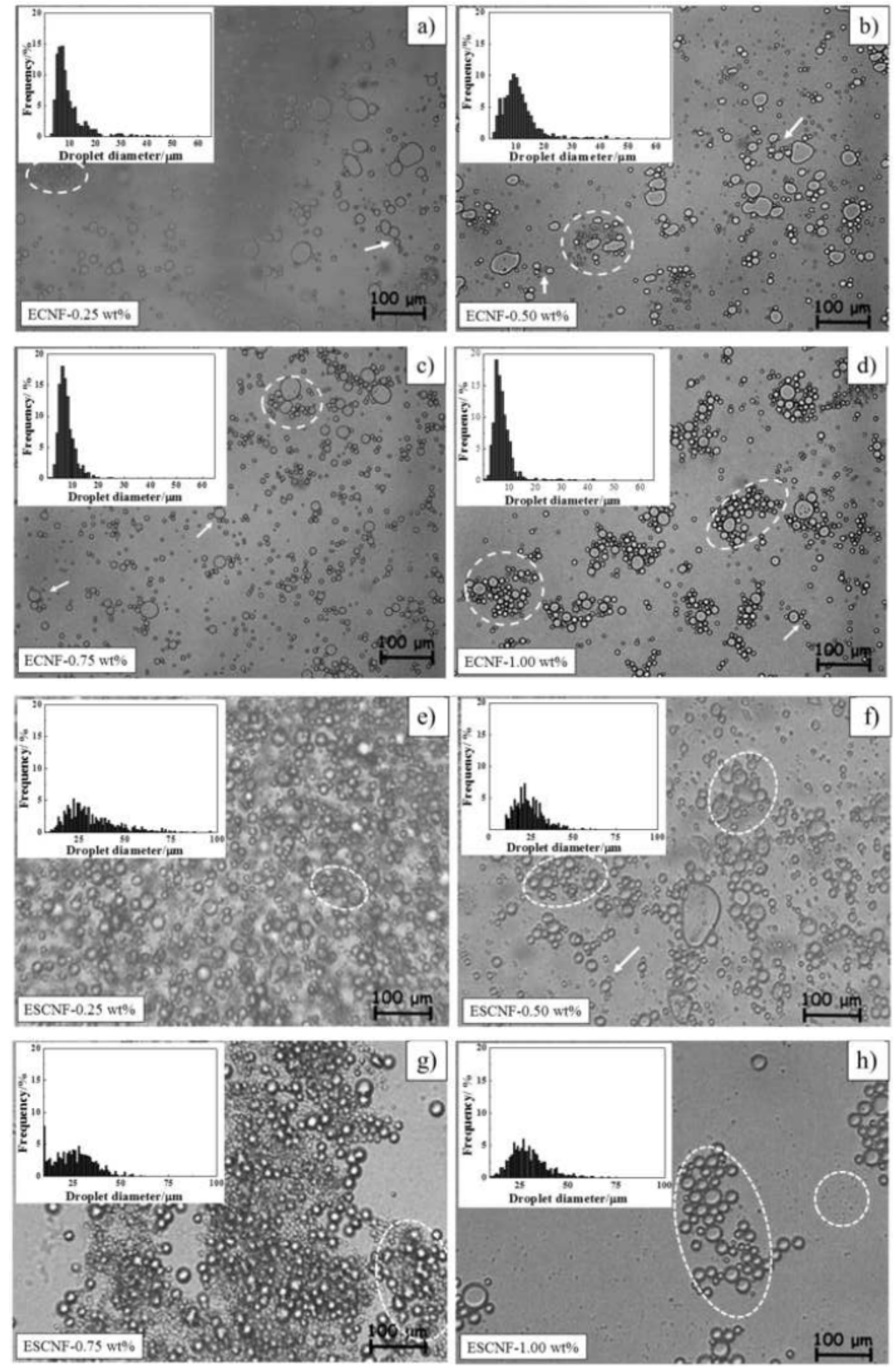

Figure 7

Optical microscopy of the ECNF (a, b, c and d) and $\operatorname{ESCNF~(e,~f,~g~and~h)~with~} 0.25,0.50,0.75,1$ wt.\% of $\mathrm{CNF}$ and SCNF. Histogram of the oil droplet diameter distribution inside the images. 


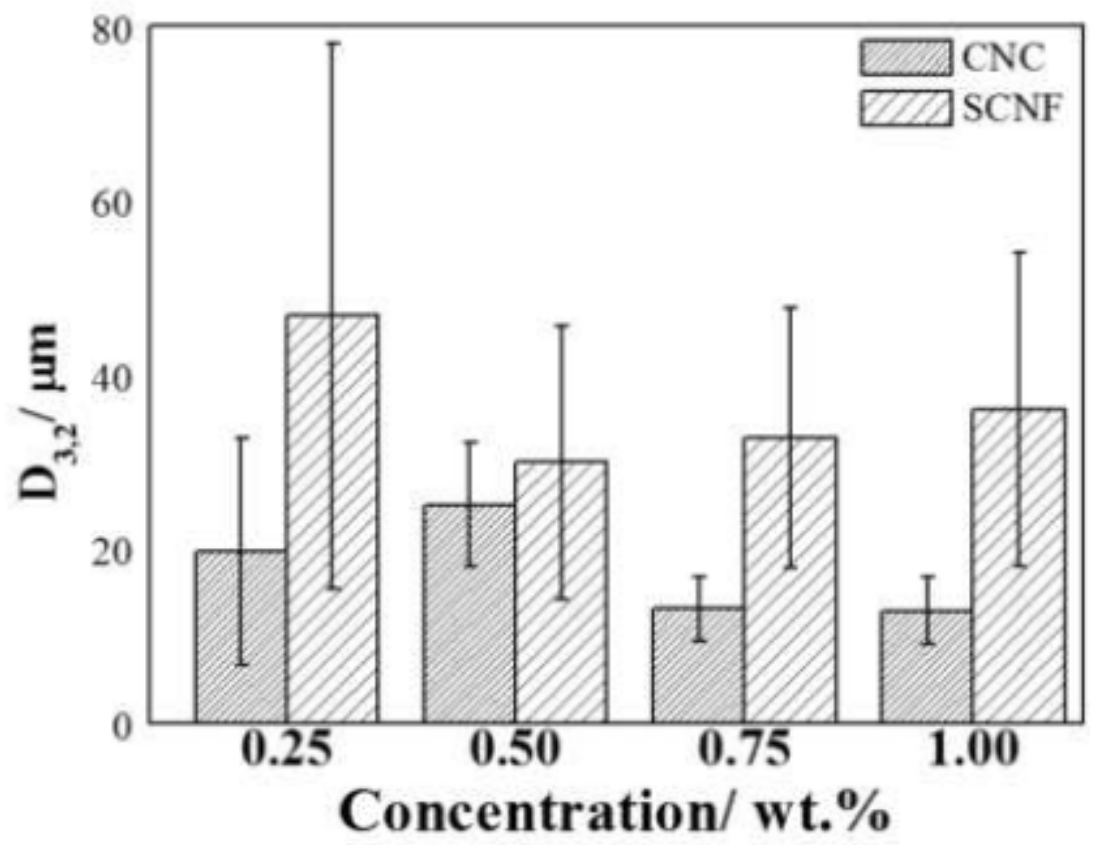

Figure 8

The Sauter diameter $(D 3,2)$ of oil dispersed droplets as a function of CNF and SCNF concentrations in the ECNF and ESCNF.
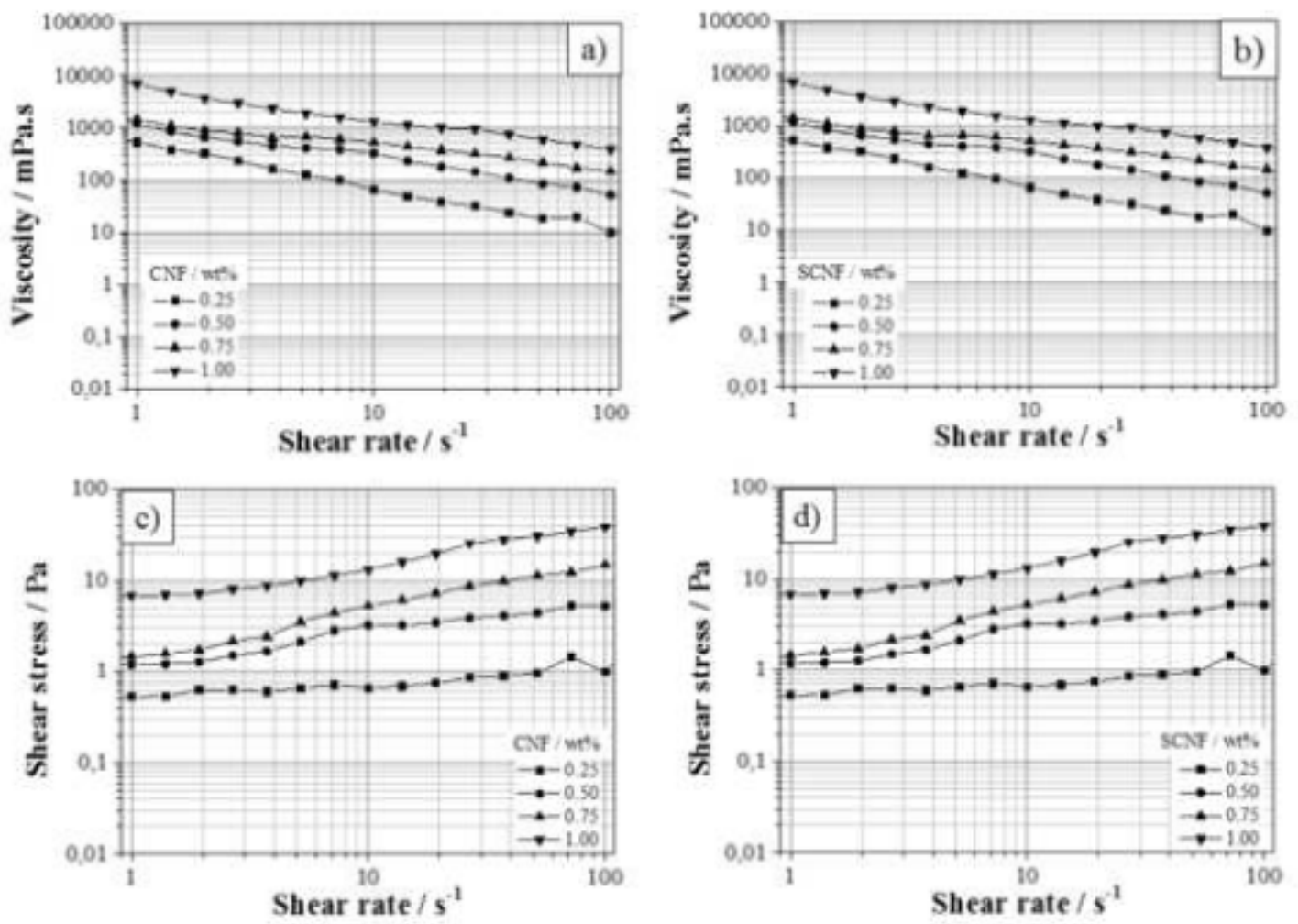

Figure 9 
Rheological behavior of ECNF and ESCNF emulsions: ( $a$ and $b$ ) Viscosity curves; ( $c$ and d) Flow curves as a function of the shear rate at $24^{\circ} \mathrm{C}$.

\section{Supplementary Files}

This is a list of supplementary files associated with this preprint. Click to download.

- graphicalabstract10.4.21.png 